\title{
Implementasi Sistem Manajemen Keselamatan dan Kesehatan Kerja pada Proyek Pembangunan Gereja Mawar Sharon Surabaya PT. Tatamulia Nusantara Indah
}

\author{
Yollananda Maha Putri Yulistina ${ }^{1}$, Jenny Caroline ${ }^{2}$ \\ 1,2 Jurusan Teknik Sipil, Fakultas Teknik Sipil dan Perencanaan, Institut Teknologi Adhi Tama Surabaya \\ Email: ${ }^{1}$ yollanandampy01@gmail.com, 2 je.carol64@gmail.com
}

\begin{abstract}
Construction project is a sort of job with extremely high risk of occupational accident compared to the other jobs. Nowadays, Tatamulia Nusantara Indah Ltd is still conducting the development of Mawar Sharon Surabaya Church which requires good management system of Occupational Health and Safety (OHS) for preventing and reducing the occupational accidents. It also aims at creating occupational environment which is safe and cozy for its workers. Therefore, this research aimed at investigating the implementation of management system of Occupational Health and Safety at Mawar Sharon Surabaya Church as well as analyzing the obstacles affecting it by distributing questionnaires to some field workers and OHS staffs. The result of data analysis demonstrated that the development of Mawar Sharon Surabaya Church had applied the management system of Occupational Health and Safety well. However, the limited time given by a company has made the workers felt uncomfortable.
\end{abstract}

Keywords: Management System of Occupational Health and Safety, Mawar Sharon Surabaya Church

\begin{abstract}
Abstrak
Proyek konstruksi merupakan suatu bidang pekerjaan dengan resiko kecelakaan kerjanya sangat tinggi di bandingkan dengan bidang pekerjaan yang lain, saat ini PT.Tatamulia Nusantara Indah sedang melaksanakan pembangunan Gereja Mawar Sharon Surabaya memerlukan sistem manajemen keselamatan dan kesehatan kerja yang baik guna dapat mencegah dan mengurangi terjadinya kecelakaan kerja dan menciptakan lingkungan kerja yang aman dan nyaman bagi pekerjanya. Tujuan penelitian ini adalah untuk mengetahui implementasi sistem manajemen keselamatan dan kesehatan kerja yang di lakukan di Gereja Mawar Sharon Surabaya dan hambatan yang dapat mempengaruhinya dengan menggunakan kuesioner yang dibagikan kepada para pekerja lapangan dan staff K3. Hasil analisis data menunjukkan bahwa pada pembangunan Gereja Mawar Sharon Surabaya telah menerapkan sistem manajemen keselamatan dan kesehatan kerja dengan baik tetapi batas waktu pekerjaan yang diberikan pihak perusahaan membuat para pekerja merasa kurang nyaman
\end{abstract}

Kata Kunci: Sistem Manajemen Keselamatan dan Kesehatan Kerja, Gereja Mawar Sharon Surabaya

\section{Pendahuluan}

Proyek konstruksi merupakan suatu bidang pekerjaan dengan tingkat resiko kecelakaan kerja sangat tinggi dibandingkan bidang pekerjaan yang lain, karena proyek konstruksi banyak menggunakan tenaga kerja manusia dan setiap kegiatan dipengaruhi oleh kondisi fisik pekerja serta lingkungan kerja, maka dari itu demikian perusahaan kontraktor diwajibkan mengimplementasikan program keselamatan kerja pada setiap proyek konstruksi yang dikerjakannya [1-6]. Penerapan program keselamatan dan kesehatan kerja secara baik dapat meminimalkan resiko terjadinya kecelakaan kerja [7]. Untuk mencegah terjadinya kecelakaan kerja pada proyek konstruksi, dibutuhkan suatu sistem manajemen keselamatan dan kesehatan kerja yang dapat mengatur dan menjadi acuan bagi kontraktor dan para 
pekerja konstruksi [8]. Penerapan Sistem Manajemen Keselamatan dan Kesehatan Kerja (SMK3) dalam pelaksanaan proyek konstruksi dapat menambah kewaspadaan serta kedisiplinan para pekerja guna membantu pencapaian nihil kecelakaan [9-10].

\section{Metode}

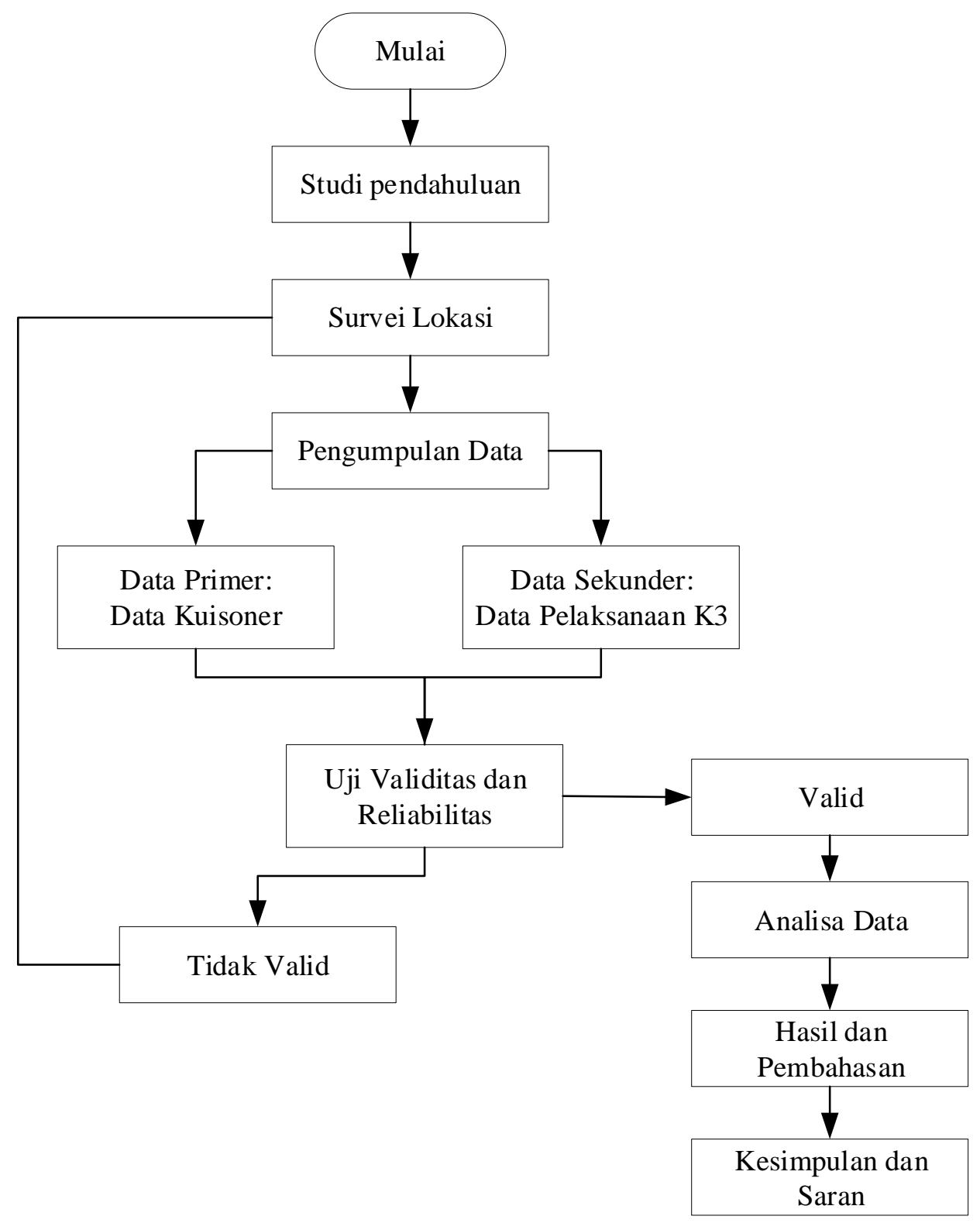

Gambar 1. Diagram alir penelitian

Berdasarkan Analisa yang dilakukan sesuai Gambar1, hal pertama yang dilakukan adalah identifikasi Pustaka berdasarkan studi pendahuluan dari penelitian sebelumnya, yang kemudian berdasarkan ploting tersebut dilakukan survei lokasi dengan mengkaraktersisasikan data menjadi data primer dan data sekunder. Yang selanjutnya dilakukan tahap validasi dan uji reliabilitas untuk mengelompokan parameter data tersebut sehingga didapatkan data valid. Bagi data yang tidak valid harus ditinjau ulang dengan menentukan lokasi survei baru, sehingga data tetap terpenuhi. 


\section{Hasil dan Pembahasan}

Berdasarkan Analisa dan surveying berdasarkan kaidah pemberian kuisoner, maka didapat beberapa data seperti yang disampaikan pada Gambar 1 - Gambar 5 yang dibagi berdasrkan jenis kelamin, usia, tingkat Pendidikan dan durasi atau lama bekerja.

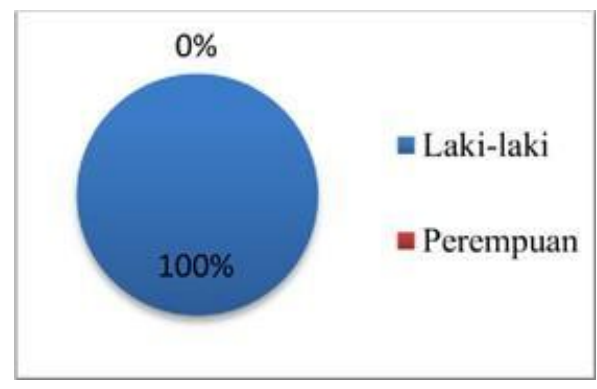

Gambar 2. Presentasi Jenis Kelamin

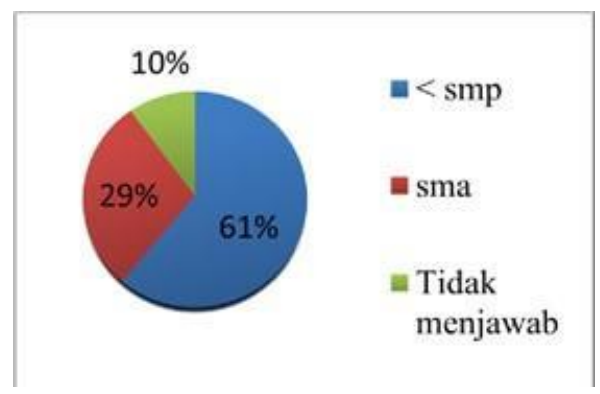

Gambar 4. Presentasi Tingkat pendidikan

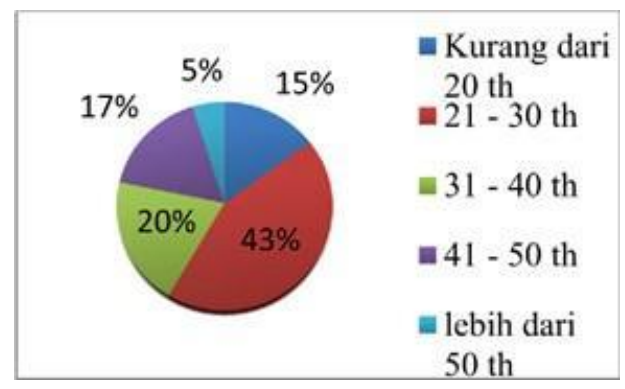

Gambar 3. Presentasi Usia

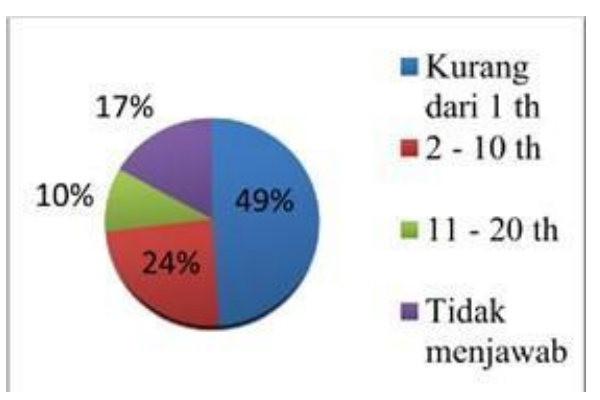

Gambar 5. Presentasi lama kerja

Tabel 1. Implementasi dan kendala Penerapan SMK3

\begin{tabular}{|c|c|c|c|c|}
\hline \multirow{2}{*}{ No } & \multirow{2}{*}{ Variabel } & \multirow{2}{*}{ Faktor } & \multicolumn{2}{|c|}{ Jawaban } \\
\hline & & & Ya & Tidak \\
\hline \multirow[b]{2}{*}{1} & \multirow{2}{*}{$\begin{array}{l}\text { Tanggung Jawab dan } \\
\text { Komitmen Perusahaan }\end{array}$} & $\begin{array}{l}\text { Adanya upaya pengawasan dari pihak perusahaan } \\
\text { terkait penerapan } \mathrm{K} 3\end{array}$ & $100 \%$ & $0 \%$ \\
\hline & & Adanya asuransi bagi para pekerja & $93 \%$ & $7 \%$ \\
\hline \multirow{8}{*}{2} & \multirow[b]{2}{*}{$\begin{array}{l}\text { Kebijakan dan Disiplin } \\
\text { K3 }\end{array}$} & $\begin{array}{l}\text { Adanya SOP atau prosedur standart penerapan K3 } \\
\text { dalam proyek pembangunan Gereja Mawar Sharon } \\
\text { Surabaya }\end{array}$ & $100 \%$ & $0 \%$ \\
\hline & & $\begin{array}{l}\text { Adanya peraturan mengenai K3 dalam proyek } \\
\text { pembangunan Gereja Mawar Sharon Surabaya }\end{array}$ & $100 \%$ & $0 \%$ \\
\hline & & $\begin{array}{l}\text { Adanya sanksi dari perusahaan apabila terjadi } \\
\text { pelanggaran pada penerapan K3 di lapangan }\end{array}$ & $98 \%$ & $2 \%$ \\
\hline & & Penggunaan APD di lingkungan kerja & $100 \%$ & $0 \%$ \\
\hline & & Pemeliharaan mesin/peralatan secara berkala & $98 \%$ & $2 \%$ \\
\hline & & Sosialisasi mengenai K3 kepada karyawan dan pekerja & $100 \%$ & $0 \%$ \\
\hline & & Adanya rambu-rambu mengenai K3 di lokasi proyek & $100 \%$ & $0 \%$ \\
\hline & & Lokasi rambu-rambu peringatan yang sesuai & $100 \%$ & $0 \%$ \\
\hline
\end{tabular}




\begin{tabular}{|c|c|c|c|c|}
\hline \multirow[b]{2}{*}{3} & \multirow{2}{*}{$\begin{array}{l}\text { Komunikasi dan } \\
\text { Penerapan } \\
\text { K3 }\end{array}$} & $\begin{array}{l}\text { Adanya safety induction tentang K3 kepada karyawan } \\
\text { dan pekerja }\end{array}$ & $100 \%$ & $0 \%$ \\
\hline & & Adanya safety officer di lapangan & $100 \%$ & $0 \%$ \\
\hline \multirow{4}{*}{4} & \multirow{4}{*}{$\begin{array}{l}\text { Inspeksi dan } \\
\text { Penyelidikan } \\
\text { Kecelakaan Kerja }\end{array}$} & Inspeksi berkala terhadap pelaksanaan proyek & $98 \%$ & $2 \%$ \\
\hline & & $\begin{array}{l}\text { Apakah terdapat prosedur evakuasi apabila terjadi } \\
\text { kejadian darurat }\end{array}$ & $95 \%$ & $5 \%$ \\
\hline & & Melakukan penyelidikan jika terjadi kecelakaan kerja & $98 \%$ & $2 \%$ \\
\hline & & $\begin{array}{l}\text { Apakah perusahaan memiliki SOP atau prosedur } \\
\text { penyelidikan kecelakaan kerja }\end{array}$ & $100 \%$ & $0 \%$ \\
\hline \multirow[t]{2}{*}{5} & \multirow[t]{2}{*}{ Evaluasi } & Audit tentang K3 & $93 \%$ & $7 \%$ \\
\hline & & Tindakan setelah audit K3 & $73 \%$ & $27 \%$ \\
\hline \multirow{7}{*}{6} & \multirow{7}{*}{ Kendala Penerapan K3 } & Adanya penjelasan penggunaan APD & $100 \%$ & $0 \%$ \\
\hline & & Jumlah APD & $100 \%$ & $0 \%$ \\
\hline & & Kenyamanan dalam penggunaan APD & $98 \%$ & $2 \%$ \\
\hline & & Mengetahui kapan penggunaan APD & $100 \%$ & $0 \%$ \\
\hline & & Mengetahui perlunya penggunaan APD & $100 \%$ & $0 \%$ \\
\hline & & Apakah para pekerja mengetahui bahasa $\mathrm{K} 3$ & $88 \%$ & $12 \%$ \\
\hline & & $\begin{array}{l}\text { Adanya batas waktu yang membuat pekerja tertekan } \\
\text { dan kurang nyaman }\end{array}$ & $46 \%$ & $54 \%$ \\
\hline
\end{tabular}

Dari total 41 responden, profil responden seluruhnya berjenis kelamin laki-laki yang rata-rata berusia 21-30 th yang merupakan usia produktif untuk bekerja, berpendidikan kurang dari SMP dan memiliki masa kerja kurang dari 2 th yang berarti sudah cukup memiliki pengalaman di bidang konstruksi.

Hasil perhitungan kuesioner untuk implementasi SMK3 menyimpulkan bahwa penerapan SMK3 sudah berjalan dengan baik. Hal itu dibuktikan dengan banyaknya jawaban "ya" berdasarkan masing-masing dimensi yaitu tanggung jawab dan komitmen perusahaan 96,5\%. Kebijakan dan disiplin K3 99,2\%. Komunikasi dan penerapan K3 100\%. Inspeksi dan penyelidikan kecelakaan kerja 97,75\%. Evaluasi $83 \%$, . Namun ada kendala yang dirasakan oleh pihak safety officer yaitu masih kurangnya kesadaran dari salah satu pihak staff yang kurang memberi contoh kepada pekerja lapangan yang membuat pekerja lapangan merasa tidak adil selain itu sebanyak $78 \%$ responden merasa kurang nyaman dengan tekanan waktu pekerjaan yang diberikan oleh perusahaan.

\section{Kesimpulan}

Berdasarkan hasil analisis dapat diambil kesimpulan sebagai berikut: (1) Penerapan sistem manajemen keselamatan dan kesehatan kerja pada proyek pembangunan Gereja Mawar Sharon Surabaya sudah berjalan dengan baik, hal itu ditunjukkan melalui persentase jawaban "ya" responden berdasarkan masing-masing dimensi yaitu tanggung jawab dan komitmen perusahaan 96,5\%, kebijakan dan disiplin K3 99,2\%, komunikasi dan penerapan K3 100\%, inspeksi dan penyelidikan kecelakaan 
kerja 97,75\%, evaluasi 83\%. Hal tersebut menunjukkan bahwa perusahaan mampu memberikan pengarahan tentang keselamatan dan kesehatan kerja kepada para pekerjanya dan menerapkannya pada proyek pembangunan Gereja Mawar Sharon Surabaya, (2) Adapun kendala yang dihadapi oleh pihak perusahaan dalam menerapkan sistem manajemen keselamatan dan kesehatan kerja berdasarkan keterangan safety officer bukanlah dari pihak pekerja lapangan melainkan dari staff perusahaan yang kurang bisa memberi contoh kepada para pekerja lapangan, selain itu sebanyak 78\% responden merasa kurang nyaman dengan tekanan waktu pekerjaan yang diberikan oleh perusahaan.

\section{Referensi}

[1] Andy Maulana, Faqih. 2010. Analisis Pelaksanaan Sistem Manajemen Keselamatan Dan Kesehatan Kerja Pada Proyek UNY YOGYAKARTA 7 IN 1. Skripsi tidak diterbitkan. Fakultas Teknik Universitas Sebelas Maret.

[2] Andi, dkk. 2018. Faktor - Faktor Penghambat Kontraktor Untuk Melaksanakan K3 Pada Proyek Konstruksi. Dimensi, Vol 1 (1) : 173-180

[3] Azizah, Aristya Noor. \& Sigit, Adityawan. 2018. Analisis Pelaksanaan Sistem Manajemen Keselamatan dan Kesehatan Kerja Pada Proyek UNY Yogyakarta 7 IN 1

[4] Haryani, Dian. 2014. Kontribusi Kecerdasan Emosi Terhadap Prestasi Belajar Serta Implikasinya Pada Bimbingan dan Konseling Skripsi tidak diterbitkan. Bandung: Fakultas Ilmu Pendidikan Universitas Pendidikan Indonesia.

[5] Mamduh (2006) Manajemen Resiko. Yogyakarta : UPP STIM YKPN Peraturan Pemerintah Republik Indonesia Nomor 50 Tahun 2012 Tentang Penerapan Sistem Manajemen Keselamatan Dan Kesehatan Kerja. 2012. Jakarta : Wirata.

[6] Ramadhan, Achmad. 2012. Penerapan Sistem Manajemen Keselamatan Dan Kesehatan Kerja (SMK3) (Studi Pada Proyek Pembangunan Jalan Rawa Buaya, Cengkareng). Skripsi tidak diterbitkan. Fakultas Ilmu Sosial dan Ilmu Politik Universitas Indonesia.

[7] Ramli, Soehatman. 2009. Sistem Manajemen Keselamatan dan Kesehatan Kerja OHSAS 18001. Jakarta: Dian Rakyat.

[8] Shafwatul, Rifat. 2017. Instrumen Penelitian Yang Valid Dan Reliabel. Dimensi, Vol 1 (1) : 1-8

[9] Sihombing, Dameyanti., Walangitan, D. R. O. \& Pratasis, Pingkan A. K. 2014. Implementasi Keselamatan dan Kesehatan Kerja (K3) Pada Proyek di Kota Bitung (Studi Kasus Proyek Pembangunan Pabrik Minyak PT.MNS). Dimensi, Vol 2 (3): 124-130.

[10] Suranto, dkk. 2004. Analisis Kepuasan Konsumen Dengan Skala Guttman, Dimensi, Vol 3 (2): 36-46 